\title{
VALORIZATION OF Cistus ladanifer AND Erica arborea SHRUBS FOR FUEL: WOOD AND BARK THERMAL CHARACTERIZATION
}

\author{
Paula Carrión-Prieto ${ }^{1}$, Pablo Martín-Ramos ${ }^{2, \bullet}$, Salvador Hernández-Navarro ${ }^{1}$, \\ Luis F. Sánchez-Sastre ${ }^{1}$, José L. Marcos-Robles ${ }^{I}$ and Jesús Martín-Gil ${ }^{1}$
}

\begin{abstract}
As a form of upgraded biomass characterized by its high energy density, low production costs, and low process energy requirements, wood pellets are an environmentally friendly fuel allowing for carbon neutral heating with high energy efficiency. In this work, the suitability of a valorization of the woods from the two most representative shrub species from the Iberian Peninsula (namely Cistus ladanifer and Erica arborea) for heating has been assessed. Whereas Erica arborea met the requirements of ISO 17225-2:2014 for ENplus-B class (the calorific content for both wood and bark was high and not significantly different, and the ash content was permissible for specimens with branch diameter $\geq 2,8 \mathrm{~cm}$ ), Cistus ladanifer was in the limit of the normative and only met the requirements in terms of acceptable ash percentage $(1,9 \%)$ and heating value $\left(19 \mathrm{~kJ} \cdot \mathrm{g}^{-1}\right)$ for old specimens with branch diameters $>3,4 \mathrm{~cm}$. Consequently, while the harvest of $E$. arborea for its use as fuel does not need to be selective, that of $C$. ladanifer should be limited to the most robust specimens and foliage should be avoided.
\end{abstract}

Keywords: Ash content, biomass resources, gum rockrose, heating values, tree heath.

\section{INTRODUCTION}

A significant proportion of Mediterranean forest vegetation consists of evergreen small diameter hardwood shrubs, such as Cistus ladanifer (gum rockrose) and Erica arborea (tree heath), which have been traditionally used as fuelwood for domestic heating purposes. In the geographic area under study (Castilla y León, Spain) both species are so abundant that their utilization as a biomass resource for energy purposes has aroused significant interest: In fact, since 2012, field studies aimed at this valorization, funded by the European Union through the LIFE+ and Joule programs, have been conducted in several municipalities in the province of Zamora (Spain). The ultimate goal would be to collect tree heath and gum rockrose for their combustion in district heating facilities (municipal boilers) in Fabero (Soria, Spain) and Las Navas del Marqués (Ávila, Spain), as well as for the electricity production plant located in Garray (Soria, Spain). Of the two bushes into consideration, the most potentially profitable would be E. arborea, whose heating value was recently reported to be the highest of all evergreen Mediterranean hardwood species (Barboutis and Lykidis 2014).

The use of biomass as an energy source provides substantial socio-economic and environmental benefits. However, bio-fuels have low bulk densities which limit their use to areas around their origin, being this drawback a restrictive factor for their energy use. Nevertheless, densification by pelleting minimizes this disadvantage. Global pellet production has considerably increased in the last years (from 7 to 19 million tons between 2006 and 2012 (Duca et al. 2014)), mainly in Europe and North America, and the growth in pellet consumption has resulted in more diversity. Consequently, the industry has

\footnotetext{
${ }^{1}$ Agriculture and Forestry Engineering Department, ETSIIAA, Universidad de Valladolid. Palencia, Spain.

${ }^{2}$ Department of Agricultural and Environmental Sciences, EPS, Instituto de Investigación en Ciencias Ambientales (IUCA),

Universidad de Zaragoza, Huesca, Spain.

•Corresponding author: pmr@unizar.es
}

Received: 21.01.2017 Accepted: 13.06.2017 
started looking for products such as wastes obtained from forestry and scrubland wood. The doubtful quality of these materials originated the development of quality standards in some countries, so as to guarantee the right use of the different types of pellets in combustion equipment.

Due to differences in chemical structure, bark and wood from C. ladanifer and E. arborea should show different properties, and -in particular- those related to their applicability as fuels. This differentiation is important because the bark of all evergreen hardwood species usually presents significantly higher ash content than wood and, in agreement with the international standard ISO 17225-2:2014 (International Organization for Standardization 2014) -which has recently superseded the European Standard EN 14961-2 for the quality characteristics of pellets (European Pellet Council 2011 )-, the threshold ash content value is $2 \%$. In this normative, the required net calorific value (NCV) or lower calorific value (LHV) is $\geq 16,56 \mathrm{~kJ} \cdot \mathrm{g}^{-1}$ and the higher heating value (HHV) is $\geq 18,82 \mathrm{~kJ} \cdot \mathrm{g}^{-1}$.

The aims of the study presented herein have been: $(i)$ to correlate the results of our analytical determinations and related calculations on HHV and ash content (AC) for bark and wood from $C$. ladanifer and E. arborea with those from other direct and indirect methods used in the literature; and (ii) to explore which bark diameters would meet the ISO 17225-2:2014 (International Organization for Standardization 2014)/ENplus (ENplus 2015) requirements for HHV and AC with a view to the valorization of these two shrub species as fuels. This is in line with the work by other authors on woods from other species (Duca et al. 2014, Miranda et al. 2017).

\section{MATERIAL AND METHODS}

The quantity known as higher heating value (also referred to as gross energy, upper heating value, gross calorific value (GCV) or higher calorific value (HCV)) is determined by bringing all the products of combustion back to the original pre-combustion temperature and, in particular, condensing any vapor produced. This is the same as the thermodynamic heat of combustion, since the enthalpy change for the reaction assumes a common temperature of the compounds before and after combustion, in which case the water produced by combustion is condensed to a liquid, hence yielding its latent heat of vaporization.

Calculations for the estimation of biomass and heating values may be obtained either by direct or by indirect methods. Direct methods involve the destruction of heavy biomass, whereas in indirect methods equations are used to estimate heating values from measurements of other variables, making the process easier (Bombelli et al. 2009).

In the first part of this study, heating values were determined by a destructive method, which comprised the selection, felling and extraction of biomass of each of the species and its subsequent combustion. C. ladanifer samples had a height of $115,3 \pm 32,4 \mathrm{~cm}$ and a crown width of 28,68 $\pm 15,25 \mathrm{~cm}$ while $E$. arborea samples had a height of $158,2 \pm 49,0 \mathrm{~cm}$ and a crown width of $103,7 \pm 60,0 \mathrm{~cm}$.

The aerial part was separated from the roots using a saw and then, following an analogous procedure to that described by Ruiz-Peinado et al. (2012), root systems were excavated by using a tractor with a shovel and then spades to complete the job. For each plant, soil was excavated down in a circular area of twice the mean crown diameter. In addition to the main body of the roots, those remaining in the hole were also collected. Samples were transported to the laboratory (ETSIIAA facilities, Universidad de Valladolid, Spain), where they were separated into different fractions and weighed (fresh weight). In the case of $C$. ladanifer, they were classified into leaves, xerochastic capsules, branches (thin: 3-7 $\mathrm{mm}$ in diameter; thick: 7-17 $\mathrm{mm}$ in diameter) and roots. On the other hand, for E. arborea -given its morphology and the impracticality of leaves separation- they were divided into four fractions: leaves with flowers and fruits, fine material $(<1 \mathrm{~cm})$, thick material $(<5 \mathrm{~cm})$ and roots, in agreement with Mello et al. (2012).

In addition to aforementioned information, the stem diameter $(2 R)$, bark thickness $(f)$ and wood and bark percentages were characterized for both species. The proportion of bark was calculated as the 
ratio of bark area in a transverse section to the total stem area of this section, according to equation (Barmpoutis et al. 2015):

$$
Z=100\left[f \frac{(2 R-f)}{R^{2}}\right]
$$

where $Z=$ bark percentage $(\%), R=$ barked stem radius $(\mathrm{cm})$ and $f=$ bark thickness $(\mathrm{cm})$.

For the determination of the bark percentage, the transverse surfaces were assumed to be circular. Consequently, bark and wood were separated and the materials were ground by means of a portable chipper. The resulting data is summarized in Table 1.

Table 1. Stem diameter and bark thickness of the shrub species under study. Values are given as an average of 10 repetitions, followed by the minimum and maximum values in brackets.

\begin{tabular}{|c|c|c|c|c|}
\hline Species & Stem diameter, $2 R(\mathrm{~cm})$ & Bark thickness, $f(\mathrm{~cm})$ & Bark, $Z(\%)$ & Wood (\%) \\
\hline C. ladanifer & $1,9(1,8-2,3)$ & $0,15(0,07-0,20)$ & 29 & 71 \\
\hline $\begin{array}{c}\text { C, ladanifer } \\
\text { (old specimens) }\end{array}$ & $3,4(2,3-4,2)$ & $0,20(0,11-0,40)$ & 22,5 & 77,5 \\
\hline E. arborea & $2,8(2,6-3,6)$ & $0,18(0,10-0,30)$ & 25 & 75 \\
\hline
\end{tabular}

It should be noted that for the study of $C$. ladanifer two sets of individuals were selected: ones with average stem diameter (1,9 cm trunk diameter) and also robust old specimens (older than 12 years, according to the equation $\mathrm{y}=1,5496 \mathrm{x}+1,5342 R^{2}$ (Valares Masa et al. 2016)), with diameters above the average, provided that this second group was more likely to meet the EN standard. Ten repetitions were carried out for each group.

Calorific values, expressed as HHV, for $C$. ladanifer and $E$. arborea fractions were calculated from elemental analysis data in agreement with the US Institute of Gas Technology (IGT) (Talwalkar et al. 1981): $\mathrm{HHV}=0,341(\% \mathrm{C})+1,322(\% \mathrm{H})-0,12(\% \mathrm{O}+\% \mathrm{~N})$, where $\% \mathrm{C}, \% \mathrm{H}, \% \mathrm{O}, \% \mathrm{~N}$ are the mass fractions in $\mathrm{wt} \%$ of dry material and $\mathrm{HHV}$ the heating value for dry material in $\mathrm{MJ} / \mathrm{kg}$. Although originally derived from data on coal, this formula has been shown to give acceptable results for a wide range of carbonaceous materials including biomass (CHPQA 2008).

Alternatively, HHV values were also calculated from holocellulose and lignine+extractives percentages, following the guidelines of Aseeva et al. (2005) and Kienzle et al. (2001) and applying a factor of 17,5 for holocellulose and of 25,5 for the lignine+extractives mixture.

Experimental HHV values were determined in a Parr 1261 isoperibol bomb calorimeter (Thermo Fisher Scientific, Waltham, MA, USA), according to the method described in BS EN 14918:2009 standard (British Standards Institution 2010). Other experimental values, such as the total enthalpy of combustion, were obtained from differential scanning calorimetry (DSC) curves by numerical integration of the experimental signal on the whole temperature range $\left(30-600{ }^{\circ} \mathrm{C}\right)$. DSC data were obtained on a TA Instruments (New Castle, DE, USA) mod. Q100 v.9.0 DSC equipped with an intracooler cooling unit at $-25^{\circ} \mathrm{C}$ (with a $1: 1$ volume mixture of ethylene glycol-water), at a heating rate $\beta=20^{\circ} \mathrm{C} / \mathrm{min}$ and at a $\mathrm{N}_{2}: \mathrm{O}_{2}$ ratio of $4: 1(20 \mathrm{~mL} / \mathrm{min})$. Samples were hermetically sealed in aluminium pans, and an empty pan was used as a reference. TG/DTG analyses were conducted with a PerkinElmer (Waltham, MA, USA) STA6000 simultaneous thermal analyser by heating the samples in a slow stream of $\mathrm{N}_{2}(20 \mathrm{~mL} / \mathrm{min})$ from room temperature up to $700{ }^{\circ} \mathrm{C}$, with a heating rate of $20^{\circ} \mathrm{C} / \mathrm{min}$. Pyris v.11 software was used for data analysis (PerkinElmer 2014). Temperature calibration was performed with high-grade standards, biphenyl (CRM LGC 2610) and indium (Perkin-Elmer, $x=99,99 \%$ ), which was also used for enthalpy calibration.

The elemental analysis and vegetal component percentages data used for above calculations, collected from 25 samples of each species with an average height (Carrión-Prieto et al. 2017), is 
summarized in Table 2. For the determination of ash content, the methodology described in ISO 18122:2015 (International Organization for Standardization 2015) was used, using 5 replicates.

Table 2. Overall chemical composition of $C$. ladanifer and $E$. arborea (Carrión-Prieto et al. 2017). Values are given as an average of 25 repetitions, followed by the minimum and maximum values in brackets.

\begin{tabular}{|c|c|c|}
\hline & Cistus ladanifer & Erica arborea \\
\hline Elemental analysis & \multicolumn{3}{|c|}{} \\
\hline C (\%) & $47,8(47,5-50,1)$ & $51,0(49,3-52,8)$ \\
\hline $\mathrm{H}(\%)$ & $6,4(6,0-6,8)$ & $6,2(6,0-6,4)$ \\
\hline $\mathrm{N}(\%)$ & $0,8(0,3-1,9)$ & $1,0(0,3-1,1)$ \\
\hline O (by diff., \%) & $\sim 45,0$ & $\sim 41,8$ \\
\hline Vegetal components & \multicolumn{3}{|c|}{} \\
\hline Cellulose (\%) & $55,0(54,9-55,7)^{*}$ & $40,0(37,3-41,1)$ \\
\hline Lignin (\%) & $25,3(24,5-34,2)$ & $39,5(39,3-40,1)$ \\
\hline Hemi-cellulose (\%) & $10,2(10,1-10,9)^{* *}$ & $11,0(9,7-13,8)^{* *}$ \\
\hline Extractive (\%) & $9,5(9,4-9,6)$ & $9,5(5,7-11,0)$ \\
\hline Moisture (wt.\%) & 26,8 & 26,0 \\
\hline
\end{tabular}

${ }^{*}$ This cellulose content is higher than that of most woods, which is usually in the $35-50 \%$ range.

${ }^{* * *}$ These hemicellulose contents are lower than those of most woods, which usually range from $20 \%$ to $30 \%$.

\section{RESULTS}

\section{HHV values calculated from the elemental analysis data}

HHV values calculated from elemental analysis data according to the IGT formula are reported in Table 3. HHV values for Cistus ladanifer, from the largest to the smallest, were: foliage $(20,53 \mathrm{~kJ} \cdot \mathrm{g}$ $\left.{ }^{1}\right)$, thin branches $\left(19,42 \mathrm{~kJ} \cdot \mathrm{g}^{-1}\right)$, thick branches $\left(19,16 \mathrm{~kJ} \cdot \mathrm{g}^{-1}\right)$ and roots $\left(19,25 \mathrm{~kJ} \cdot \mathrm{g}^{-1}\right)$. The result for branches was in close agreement with that reported by Dimitrakopoulos and Panov (2001) (viz. 19,05 $\left.\mathrm{kJ} \cdot \mathrm{g}^{-1}\right)$.

HHV values for Erica arborea, from the largest to the smallest, were: foliage $\left(21,29 \mathrm{~kJ} \cdot \mathrm{g}^{-1}\right)$, thick branches $\left(19,69 \mathrm{~kJ} \cdot \mathrm{g}^{-1}\right)$, thin branches $\left(20,12 \mathrm{~kJ} \cdot \mathrm{g}^{-1}\right)$, roots $\left(19,91 \mathrm{~kJ} \cdot \mathrm{g}^{-1}\right)$ and stem wood $\left(19,8 \mathrm{~kJ}^{-1} \cdot \mathrm{g}^{-1}\right)$. These results were in reasonably good agreement with those reported by Dimitrakopoulos and Panov (2001) for foliage $\left(23,59 \mathrm{~kJ} \cdot \mathrm{g}^{-1}\right)$ and branches $\left(19,34 \mathrm{~kJ} \cdot \mathrm{g}^{-1}\right)$.

Table 3. Carbon $(\mathrm{C})$, hydrogen $(\mathrm{H})$, nitrogen $(\mathrm{N})$ and oxygen $(\mathrm{O})$ percentages for $C$. ladanifer and $E$. arborea fractions and HHV values calculated thereof.

\begin{tabular}{|c|c|c|c|c|c|c|c|c|}
\hline & \multicolumn{4}{|c|}{ Cistus ladanifer } & \multicolumn{4}{c|}{ Erica arborea } \\
\cline { 2 - 9 } & Leaves & Thin branches & Thick branches & Roots & Leaves & Thin branches & Thick branches & Roots \\
\hline \multirow{2}{*}{$\mathrm{C}(\%)$} & 50,07 & 48,12 & 47,56 & 47,76 & 52,82 & 49,34 & 50,26 & 49,82 \\
& $(0,04)$ & $(0,03)$ & $(0,06)$ & $(0,05)$ & $(0,02)$ & $(0,01)$ & $(0,03)$ & $(0,12)$ \\
\hline \multirow{2}{*}{$\mathrm{H}(\%)$} & 6,4 & 6,4 & 6,4 & 6,4 & 6,2 & 6,2 & 6,2 & 6,2 \\
\cline { 2 - 10 } & $(0,2)$ & $(0,2)$ & $(0,2)$ & $(0,2)$ & $(0,2)$ & $(0,2)$ & $(0,2)$ & $(0,2)$ \\
\hline \multirow{2}{*}{$\mathrm{N}(\%)$} & 1,89 & 0,84 & 0,27 & 0,36 & 1,05 & 0,34 & 0,38 & 0,34 \\
& $(0,00)$ & $(0,00)$ & $(0,02)$ & $(0,00)$ & $(0,00)$ & $(0,02)$ & $(0,00)$ & $(0,02)$ \\
\hline O (by diff.\%) & 41,64 & 44,60 & 45,77 & 45,48 & 39,93 & 44,12 & 43,16 & 43,64 \\
\hline HHV (kJ·g-1) & 20,53 & 19,42 & 19,16 & 19,25 & 21,29 & 19,69 & 20,12 & 19,91 \\
\hline
\end{tabular}


All values for the elemental analysis are given in average \pm standard deviations (in brackets) across five replicates. The value for $C$. ladanifer capsules has been omitted due to its low representativeness and to allow comparison of the components of both species.

\section{HHV values calculated from the component percentages}

Using the percentage of biomass distribution in each plant (Table 4), overall HHV for both shrubs was readily calculated.

Table 4. Percentage of biomass distribution in each plant (Carrión-Prieto et al. 2017).

\begin{tabular}{|c|c|c|}
\hline \multirow{2}{*}{ Component } & \multicolumn{2}{|c|}{ Component percentage } \\
\cline { 2 - 3 } & Cistus ladanifer & Erica arborea \\
\hline Leaves (\%) & 19 & 4 \\
\hline Capsules (\%) & 1 & - \\
\hline Thin branches (\%) & 29 & 20 \\
\hline Thick branches (\%) & 33 & 41 \\
\hline Roots (\%) & 18 & 35 \\
\hline
\end{tabular}

All values are given in average across 25 samples of each species.

Because $C$. ladanifer has $19 \%$ of leaves $\left(\times 20,53 \mathrm{~kJ} \cdot \mathrm{g}^{-1}=3,87 \mathrm{~kJ} \cdot \mathrm{g}^{-1}\right), 29 \%$ of thin branches $(\times 19,42$ $\left.\mathrm{kJ} \cdot \mathrm{g}^{-1}=5,655 \mathrm{~kJ} \cdot \mathrm{g}^{-1}\right), 33 \%$ of thick branches $\left(\times 19,16 \mathrm{~kJ} \cdot \mathrm{g}^{-1}=6,346 \mathrm{~kJ} \cdot \mathrm{g}^{-1}\right)$ and $18 \%$ of roots $(\times 19,25$ $\left.\mathrm{kJ} \cdot \mathrm{g}^{-1}=3,478 \mathrm{~kJ} \cdot \mathrm{g}^{-1}\right)$, the resultant HHV weighted average was $19,3 \mathrm{~kJ} \cdot \mathrm{g}^{-1}$. Likewise, E. arborea, with $4 \%$ of leaves $\left(\times 21,29 \mathrm{~kJ} \cdot \mathrm{g}^{-1}=0,855 \mathrm{~kJ} \cdot \mathrm{g}^{-1}\right), 20 \%$ of branches $\left(\times 19,69 \mathrm{~kJ} \cdot \mathrm{g}^{-1}=3,952 \mathrm{~kJ} \cdot \mathrm{g}^{-1}\right), 41 \%$ of thick branches $\left(\times 20,12 \mathrm{~kJ} \cdot \mathrm{g}^{-1}=8,28 \mathrm{~kJ} \cdot \mathrm{g}^{-1}\right)$ and $35 \%$ of roots $\left(\times 19,91 \mathrm{~kJ} \cdot \mathrm{g}^{-1}=7,0 \mathrm{~kJ} \cdot \mathrm{g}^{-1}\right)$, yielded a HHV weighted average of $20,0 \mathrm{~kJ} \cdot \mathrm{g}^{-1}$.

By applying the weighted average formulas and percentages of bark and wood from Table 1, it was possible to estimate HHV values of $19,5 \mathrm{~kJ} \cdot \mathrm{g}^{-1}$ (bark) and $19,3 \mathrm{~kJ} \cdot \mathrm{g}^{-1}$ (wood) for random C. ladanifer specimens, and of $19,6 \mathrm{~kJ} \cdot \mathrm{g}^{-1}$ (bark) and $19,2 \mathrm{~kJ} \cdot \mathrm{g}^{-1}$ (wood) for old specimens. As regards E. arborea, the bark and wood HHV values were $20,6 \mathrm{~kJ} \cdot \mathrm{g}^{-1}$ and $19,9 \mathrm{~kJ} \cdot \mathrm{g}^{-1}$, respectively. If, alternatively, the HHV values were calculated from the maximum holocellulose and lignin+extractives percentages (Table 2) using the factors proposed by Aseeva et al. (2005) and Kienzle et al. (2001) for such fractions, the results obtained were $20,2 \mathrm{~kJ} \cdot \mathrm{g}^{-1}$ for $C$. ladanifer and $22,1 \mathrm{~kJ} \cdot \mathrm{g}^{-1}$ for E. arborea.

\section{HHV experimental values from calorimetry}

HHV, determined with an isoperibol bomb calorimeter, according to the method described in the EN 14918:2009 standard, yielded values of $19,7 \mathrm{~kJ} \cdot \mathrm{g}^{-1}$ for C. ladanifer and $21,0 \mathrm{~kJ} \cdot \mathrm{g}^{-1}$ for E. arborea.

\section{Results from DSC and TG/DTG curves}

DSC curves for C. ladanifer and E. arborea woods are shown in Figure 1 and their thermal effects (mainly due to holocellulose and lignin combustion) are summarized in Table 5. Overall enthalpy change values obtained from these curves resulted in $18,04 \mathrm{~kJ} \cdot \mathrm{g}^{-1}$ and $18,63 \mathrm{~kJ} \cdot \mathrm{g}^{-1}$, respectively. 

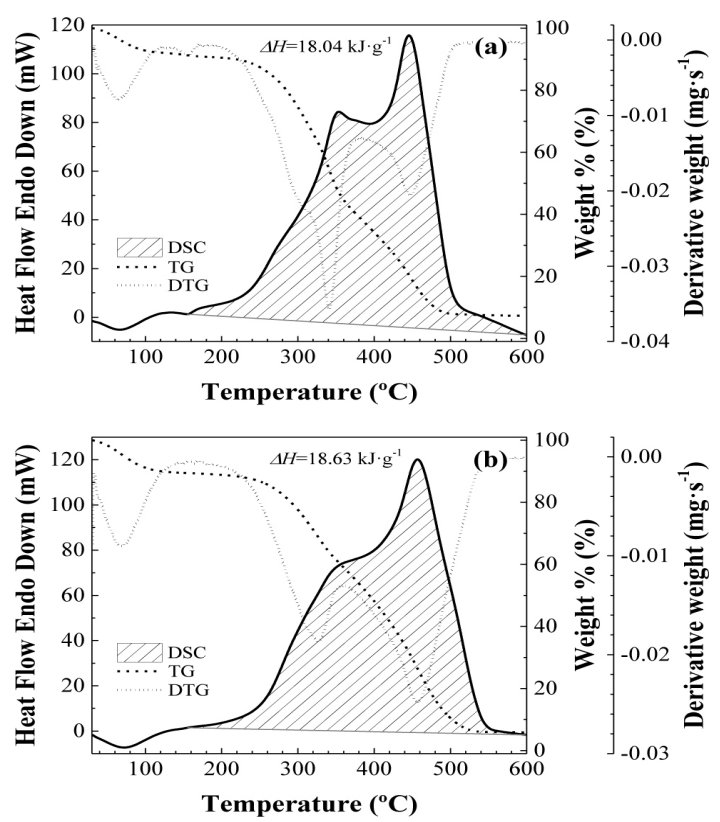

Figure 1. DSC and TG/DTG curves of (a) C. ladanifer and (b) E. arborea woods.

Table 5. Exothermic effects data for holocellulose and lignin in the DSC thermograms for $C$. ladanifer and E. arborea woods.

\begin{tabular}{|c|c|c|c|c|c|}
\hline \multirow{2}{*}{} & \multicolumn{2}{|c|}{ Holocellulose (cellulose+hemicellulose) } & \multicolumn{2}{|c|}{ Lignin } & Overall enthalpy change \\
\cline { 2 - 6 } & $\mathrm{T}_{\text {peak }}\left({ }^{\circ} \mathrm{C}\right)$ & $\mathrm{T}_{\text {offset }}\left({ }^{\circ} \mathrm{C}\right)$ & $\mathrm{T}_{\text {peak }}\left({ }^{\circ} \mathrm{C}\right)$ & $\mathrm{T}_{\text {offset }}\left({ }^{\circ} \mathrm{C}\right)$ & $\Delta H\left(\mathrm{~kJ} . \mathrm{g}^{-1}\right)$ \\
\hline C. ladanifer & 365 & & 455 & 479 & 18,04 \\
\hline E. arborea & 376 & 392 & 527 & 535 & 18,63 \\
\hline
\end{tabular}

$\mathrm{T}_{\text {peak }}$ stands for the temperature at which the maximum mass loss occurred, according to TG/DTG measurements; $\mathrm{T}_{\text {offset }}$ stands for the temperature at which the maximum value of heat flux occurred, obtained from the DSC thermograms.

The ash content of the various fractions of $C$. ladanifer and $E$. arborea was estimated from the residue after heating at $700{ }^{\circ} \mathrm{C}$ (Figures 2, 3, 4 and 5), according to the usual temperature conditions for pyrolysis in oxygen bomb calorimeters (Wang et al. 2016). Both the inner and outer parts of the stem and those of the epidermis and cortex of the roots of $C$. ladanifer resulted in percentage values ranging from $0,5 \%$ to $0,6 \%$ with no significant differences between fractions. Conversely, for $E$. arborea, the percentages for the stem outer part and the root epidermis ranged from 0,6 to $0,9 \%$, while those for the inner parts of the root and the stem were $0,19 \%$ and $0,36 \%$, respectively. It is worth noting that all these values were below $2 \%$. 

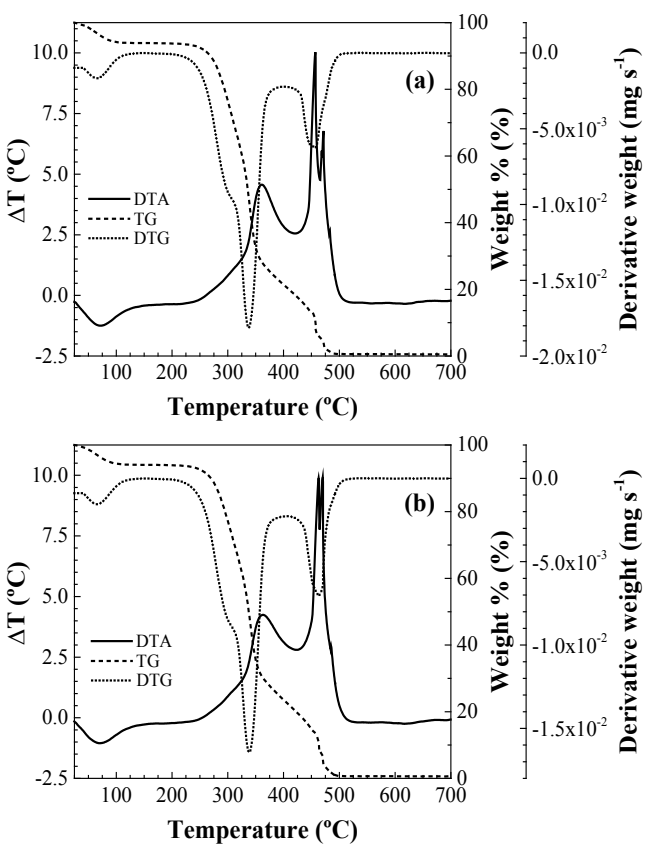

Figure 2. DTA and TG/DTG curves of $C$. ladanifer stems: (a) external fraction and (b) internal fraction.
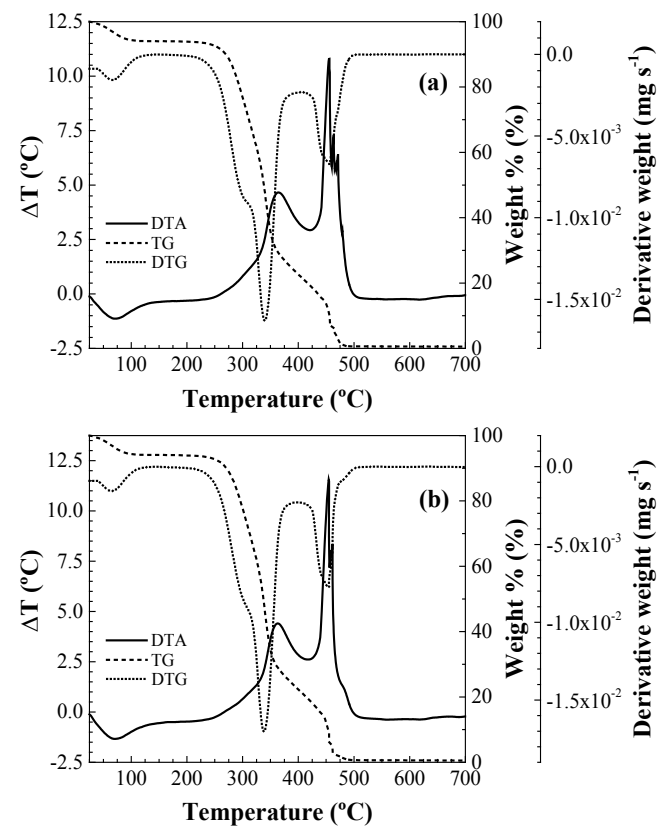

Figure 3. DTA and TG/DTG curves of C. ladanifer roots: (a) epidermis and (b) cortex. 

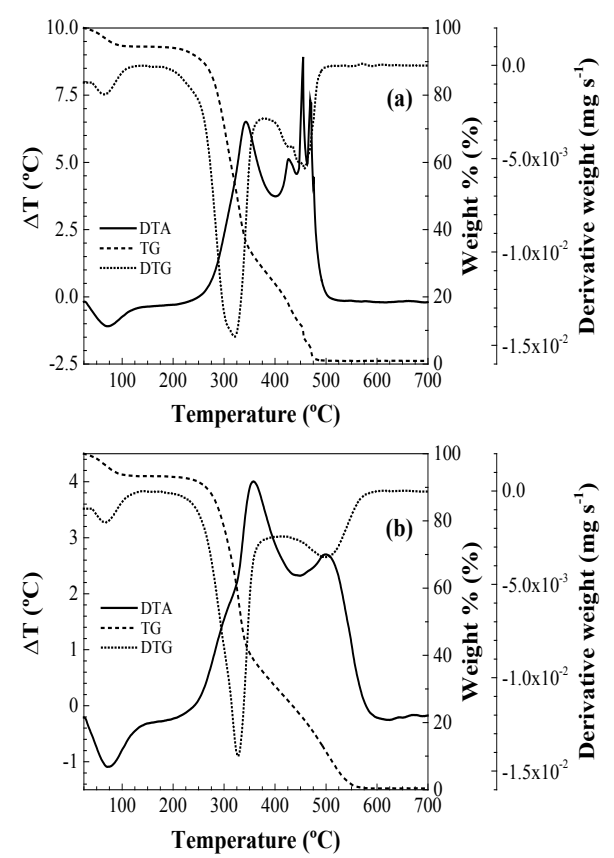

Figure 4. DTA and TG/DTG curves of E. arborea stems: (a) external fraction and (b) internal fraction.
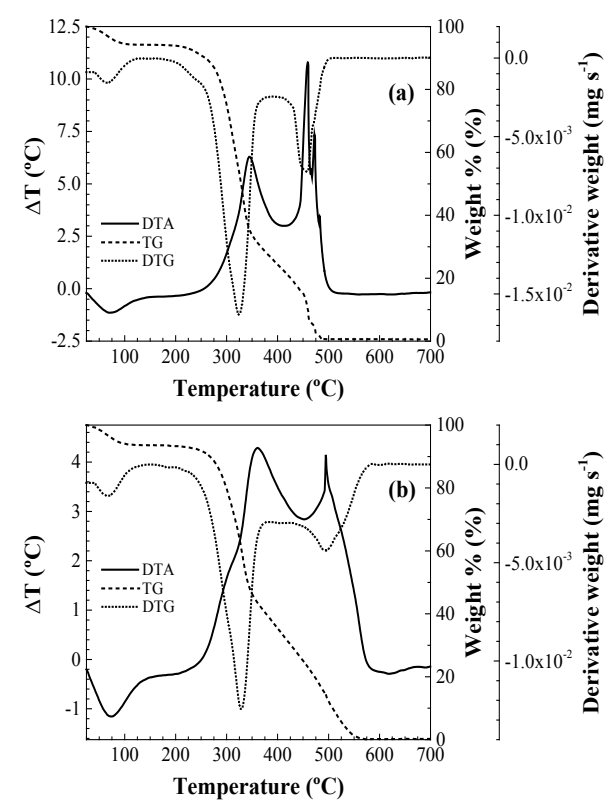

Figure 5. DTA and TG/DTG curves of E. arborea roots: (a) epidermis and (b) cortex.

\section{Ash content from UNE-EN ISO 18122:2015 method}

Overall experimental ash content values obtained according UNE-EN ISO 18122:2015 norm (International Organization for Standardization 2015) for C. ladanifer and E. arborea were 1,9\% and $1,6 \%$ dry weight, respectively. When the ash percentage was broken down for each of the fractions, for C. ladanifer it followed the order: foliage $(9,0 \%)>$ stem bark $(7,0-6,5 \%)>$ roots $(1,4 \%)>$ branches $(1,1 \%)>$ stem wood $(0,7-0,6 \%)$. Likewise, for Erica arborea the AC order followed was: foliage 
$(5,5 \%)>$ stem bark $(5,0-4,6 \%)>\operatorname{roots}(1,7 \%)>$ branches $(1,1 \%)>$ stem wood $(0,5 \%)$. Simplified data for bark and wood fractions is shown in Table 6.

Table 6. Experimental values for ash content (AC) from bark and wood fractions.

\begin{tabular}{|c|c|c|c|}
\hline & Overall AC (\%) & Bark AC (\%) & Wood AC (\%) \\
\hline C. ladanifer & 2,45 & 7,0 & 0,7 \\
\hline C. ladanifer (old specimens) & 1,9 & 6,5 & 0,6 \\
\hline E. arborea & 1,6 & 5,0 & 0,5 \\
\hline
\end{tabular}

Values are given in average across 5 repetitions.

\section{DISCUSSION}

The experimental and calculated HHV values for $C$. ladanifer specimens of indiscriminate age were in the 19,0-19,4 range, as compared to $19,2-20,2 \mathrm{~kJ} \cdot \mathrm{g}^{-1}$ for old specimens. These results were slightly higher than those reported (according to the superseded EN 14775 norm) by García Rosa (2013) $\left(17,8 \mathrm{~kJ} \cdot \mathrm{g}^{-1}\right)$ and Martínez et al. (2000) $\left(17,9 \mathrm{~kJ} \cdot \mathrm{g}^{-1}\right)$, and slightly lower than those reported by Marques et al. (2011) $\left(21,4 \mathrm{~kJ} \cdot \mathrm{g}^{-1}\right)$. Analogous results for E. arborea were in the $19,9-22,1 \mathrm{~kJ}^{-1} \cdot \mathrm{g}^{-1}$ range, in excellent agreement with those reported by Zabaniotou et al. (2000) $\left(20,58 \mathrm{~kJ} \cdot \mathrm{g}^{-1}\right)$ and Tihay et al. (2009) $\left(21,4 \mathrm{~kJ}^{-1} \mathrm{~g}^{-1}\right)$ and somewhat higher than those reported by Barmpoutis et al. $(2015)(19,95$ $\left.\mathrm{kJ} \cdot \mathrm{g}^{-1}\right)$.

Whole enthalpy change values from thermal analysis were around $18,04 \mathrm{~kJ} \cdot \mathrm{g}^{-1}$ and $18,63 \mathrm{~kJ} \cdot \mathrm{g}^{-1}$ for $C$. ladanifer and $E$. arborea, respectively. These values can be assigned to low heating values (LHV), provided that they would be in good agreement with those expected from the holocellulose and lignin net calorific values (ca. $17 \mathrm{~kJ} \cdot \mathrm{g}^{-1}$ and ca. $21 \mathrm{~kJ} \cdot \mathrm{g}^{-1}$, respectively (Energy research Centre of the Netherlands 2012)) and the percentages reported in Table 2. In fact, the value reported in the literature for the LHV of C. ladanifer is $17,9 \mathrm{~kJ}^{-1} \mathrm{~g}^{-1}$ (Martínez et al. 2000), very close to the one reported herein.

The ash values obtained for randomly-chosen specimens of $C$. ladanifer according to UNE-EN ISO 18122:2015 (International Organization for Standardization 2015) testing standard were lower than those referred by Ferro et al. (2015) (3,0-3,2\%) and Marques et al. (2011) (whole plant 3,1\%; wood $0,8 \%$ ), determined according to earlier EN norms, and were in agreement with those informed by Martínez et al. (2000) (2,3\%). For E. arborea, results presented in this study were lower than those reported by Dimitrakopoulos and Panov (2001) (2,5\% for leaves and 1,6\% branches), Doat et al. (1981) (2,4\%) and Boubaker et al. (2004) (3,5\%).

Regarding the ash content broken down for each of the fractions, the highest value was obtained for stem bark (around 6,0\%), thus identifying this fraction as the one which compromises the use of these shrubs as fuelwood.

In terms of the requirements of ISO 17225-2:2014 (International Organization for Standardization 2014) for ash content of pellets (ENplus-B class) and in view of Table 7, C. ladanifer stems with a diameter of $1,9 \mathrm{~cm}$ would be non-compliant, while those with diameters over $3,4 \mathrm{~cm}$ would be acceptable. Consequently, we propose this minimum barked diameter to produce pellets of ENplus-B class. The barked diameter value proposed for E. arborea is entirely coincident with that suggested by Barboutis and Lykidis (2014) following the EN 14961-2 norm.

Table 7. Minimum barked diameter to meet the requirements of ISO 17225-2:2014 norm (International Organization for Standardization 2014) for ash content of pellets and associated HHV values.

\begin{tabular}{|c|c|c|c|c|}
\hline & Diameter $(\mathrm{cm})$ & Ash $(\%)$ & EN class & HHV $\left(\mathrm{kJ}^{\circ} \cdot \mathrm{g}^{-1}\right)$ \\
\hline C. ladanifer & 3,40 & 1,9 & ENplus $\mathrm{B}$ & 19,2 \\
\hline E. arborea & 2,80 & 1,5 & ENplus B & 19,9 \\
\hline
\end{tabular}




\section{CONCLUSIONS}

One of the requirements of current European standards concerning biofuels in the form of pellets for their use in rural district heating is the ash percentage maximum, limited to $2 \%$. Ash content is significantly influenced by the bark and foliage percentages of the plants to be used as fuel. Both shrub species under study, $C$. ladanifer and $E$. arborea, yielded HHV values that met the requirements established in the regulations for their use as fuel. However, only the ash contents for E. arborea were compliant without ambiguity. In the case of $C$. ladanifer, biomass ash percentage was in the upper limit of the normative and this would be a problem for its acceptance as fuelwood. To ensure its adequacy, only old specimens (with stem diameters ranging from 2 to $4,8 \mathrm{~cm}$ ) should be harvested, avoid foliage.

\section{ACKNOWLEDGMENTS}

Financial support by the European Union LIFE+ Programme, under project " $\mathrm{CO}_{2}$ Operation: Integrated agroforestry practices and nature conservation against climate change" (ref. LIFE11 ENV/ ES/000535), is gratefully acknowledged. Access to TAIL-UC facility, funded under QREN-Mais Centro Project ICT_2009_02_012_1890 is also acknowledged.

\section{REFERENCES}

Aseeva, R.M.; Thanh, B.D.; Serkov, B.B. 2005. Factors Affecting Heat Release at the Combustion of the Different Species of Wood. In Berlin, A.A.; Novakov, I.A.; Khalturinskiy, N.A.; Zaikov, G.E. eds. Chemical Physics of Pyrolysis, Combustion, and Oxidation. New York, USA. Nova Science Publishers pp. 45-53.

Barboutis, I.; Lykidis, C. 2014. The effects of bark on fuel characteristics of some evergreen Mediterranean hardwood species. In Proceedings of the $57^{\text {th }}$ International Convention of Society of Wood Science and Technology, Zvolen, Slovakia. pp. 533-540.

Barmpoutis, P.; Lykidis, C.; Barboutis, I. 2015. Influence of stem diameter and bark ratio of evergreen hardwoods on the fuel characteristics of the produced pellets. Pro Ligno 11(4): 673-679.

Bombelli, A.; Avitabile, V.; Balzter, H.; Marchesini, L.B.; Bernoux, M.; Brady, M.; Hall, R.; Hansen, M.; Henry, M.; Herold, M.; Janetos, A.; Law, B.E.; Manlay, R.; Marklund, L.G.; Olsson, H.; Pandey, D.; Saket, M.; Schmullius, C.; Sessa, R.; Shimabukuro, Y.E.; Valentini, R.; Wulder, M. 2009. T12 Assessment of the status of the development of the standards for the Terrestrial Essential Climate Variables: Biomass. Rome, Italy: Global Terrestrial Observing System Secretariat, Land and Water Division (NRL), Food and Agriculture Organization of the United Nations (FAO). 30 pp. [Available at] <ftp://ftp.fao.org/docrep/fao/012/i1238e/i1238e00.pdf $>$.

Boubaker, A.; Kayouli, C.; Boukary, A.; Buldgen, A. 2004. Chemical and biological characterisation of some woody species browsed by goats in the North-West of Tunisia. In Ben Salem, H.; Morand-Fehr, P.; Nefzaoui, A. eds. Nutrition and feeding strategies of sheep and goats under harsh climates. Zaragoza, Spain. CIHEAM. pp. 147-151.

British Standards Institution. 2010. BS EN 14918:2009, Solid biofuels. Determination of calorific value. London, UK: British Standards Institution. 64 pp. [Available at] <http://shop.bsigroup. $\mathrm{com} /$ ProductDetail/?pid=000000000030198715>.

Carrión-Prieto，P.; Hernández-Navarro，S.; Martín-Ramos，P.; Sánchez-Sastre， L.F.; 
Garrido-Laurnaga, F.; Marcos-Robles, J.L.; Martín-Gil, J. 2017. Mediterranean shrublands as carbon sinks for climate change mitigation: new root-to-shoot ratios. Carbon Management 8(1): 1-11.

CHPQA. 2008. Guidance Note 29: Alternative fuels - Energy inputs. London, UK: UK Combined Heat \& Power Quality Assurance Programme. 6 pp. [Available at] <https://www.chpqa.com/guidance notes/GUIDANCE_NOTE_29.pdf $>$.

Dimitrakopoulos, A.P.; Panov, P.I. 2001. Pyric properties of some dominant Mediterranean vegetation species. International Journal of Wildland Fire 10(1): 23-27.

Doat, J.; Valette, J.C.; Askri, D.; Caumartin, L.; Bettachini, M.; Moro, M. 1981. Le pouvoir calorifique supérieur d'espèces forestières méditerranéennes. Annales des Sciences forestières 38(4): 469-486.

Duca, D.; Riva, G.; Foppa Pedretti, E.; Toscano, G. 2014. Wood pellet quality with respect to EN 14961-2 standard and certifications. Fuel 135: 9-14.

Energy research Centre of the Netherlands. 2012. ECN Phyllis2 database for biomass and waste. [online] $<$ https://www.ecn.nl/phyllis2 $>$ [cit. 06/08/2017].

ENplus. 2015. ENplus Handbook version 3.0. Brussels, Belgium: European Biomass Association AEBIOM,. 103 pp. [Available at] <http://www.enplus-pellets.eu/downloads/enplus-handbook/>.

European Pellet Council. 2011. Handbook for the Certification of Wood Pellets for Heating Purposes, based on EN 14961-2. Brussels, Belgium: European Pellet Council. 33 pp. [Available at] $<$ http://www.pelletcouncil.eu/cms/wp-content/uploads/2011/02/ENplus-handbook-3.5.11.pdf>.

Ferro, M.D.; Fernandes, M.C.; Paulino, A.F.C.; Prozil, S.O.; Gravitis, J.; Evtuguin, D.V.; Xavier, A.M.R.B. 2015. Bioethanol production from steam explosion pretreated and alkali extracted Cistus ladanifer (rockrose). Biochemical Engineering Journal 104: 98-105.

García Rosa, M. 2013. Estudio de la biomasa de Cistus ladanifer L. y Retama sphaerocarpa L. como sumidero de $\mathrm{CO}_{2}$ : existencias y potencialidad. $\mathrm{PhD}$ Thesis. Badajoz, Spain. Departamento de Biología Vegetal, Ecología y Ciencias de la Tierra, Universidad de Extremadura. 230 pp.

International Organization for Standardization. 2014. 17225-2:2014 Solid biofuels, Fuel specifications and classes. Part 2: Graded wood pellets. Geneva, Switzerland: International Organization for Standardization. 9 pp. [Available at] <http://www.iso.org/iso/catalogue_detail?csnumber $=59457>$.

International Organization for Standardization. 2015. 18122:2015, Solid biofuels, Determination of ash content. Geneva, Switzerland: International Organization for Standardization. 6 pp. [Available at] $<$ http://www.iso.org/iso/home/store/catalogue tc/catalogue_detail.htm?csnumber=61515>.

Kienzle, E.; Schrag, I.; Butterwick, R.; Opitz, B. 2001. Calculation of gross energy in pet foods: new data on heat combustion and fibre analysis in a selection of foods for dogs and cats. Journal of Animal Physiology and Animal Nutrition 85(5-6): 148-157.

Marques, E.; Paiva, J.M.; Pinho, C. 2011. The new Portuguese energy challenge? Pellets from shrubs. In Proceedings of the $21^{\text {st }}$ Brazilian Congress of Mechanical Engineering, October 24-28, 2011. Natal, RN, Brazil. pp. 12.

Martínez, J.M.; Varela, M.; Escalada, R.; Murillo, J.M.; González, E.; Carrasco, J.; Manzanares, P. 2000. Combustion assays of brushwood (Cistus ladanifer) biomass in a BAFB pilot plant. In Proceedings of the $1^{\text {st }}$ World Conference on Biomass for Energy and Industry, June 5-9, 2000. Sevilla, Spain. pp. 1987-1990.

Mello, A.A.d.; Nutto, L.; Weber, K.S.; Sanquetta, C.E.; Matos, J.L.M.d.; Becker, G. 2012. 
Individual biomass and carbon equations for Mimosa scabrella Benth. (Bracatinga) in Southern Brazil. Silva Fennica 46(3): 333-343.

Miranda, I.; Mirra, I.; Gominho, J.; Pereira, H. 2017. Fractioning of bark of Pinus pinea by milling and chemical characterization of the different fractions. Maderas. Ciencia y tecnología 19(2): 185-194.

PerkinEImer. 2014. Pyris - Instrument Managing Software, Version 11. Waltham, MA, USA: PerkinElmer, Inc.

Ruiz-Peinado, R.; Montero, G.; Del Rio, M. 2012. Biomass models to estimate carbon stocks for hardwood tree species. Forest Systems 21(1): 42-52.

Talwalkar, A.T.; United, S.; Department of, E.; Institute of Gas, T. 1981. IGT/DOE coalconversion systems technical data book, Chicago, IL, USA. Institute of Gas Technology. 23 pp.

Tihay, V.; Santoni, P.-A.; Simeoni, A.; Garo, J.-P.; Vantelon, J.-P. 2009. Skeletal and global mechanisms for the combustion of gases released by crushed forest fuels. Combustion and Flame 156(8): 1565-1575.

Valares Masa, C.; Sosa Díaz, T.; Alías Gallego, J.; Chaves Lobón, N. 2016. Quantitative variation of flavonoids and diterpenes in leaves and stems of Cistus ladanifer L. at different ages. Molecules 21(3): 275-288.

Wang, F.; Hu, L.J.; Zheng, Y.W.; Huang, Y.B.; Yang, X.Q.; Liu, C.; Kang, J.; Zheng, Z.F. 2016. Regulation for Optimal Liquid Products during Biomass Pyrolysis: A Review. IOP Conference Series: Earth and Environmental Science 40: 012047.

Zabaniotou, A.A.; Roussos, A.I.; Koroneos, C.J. 2000. A laboratory study of cotton gin waste pyrolysis. Journal of Analytical and Applied Pyrolysis 56(1): 47-59. 